\title{
Forecasting the Demand of Oil in Ghana: A Statistical Approach
}

\author{
Valentina Boamah", ${ }^{1, *}$ \\ ${ }^{1}$ School of Business, Nanjing University of Information Science and Technology, Nanjing, China \\ *Corresponding author: maafiavalentine@gmail.com
}

Received 30 June 2021; Revised 6 July 2021; Accepted 7 July 2021

\begin{abstract}
Oil plays a vital role in the economic growth and sustainability of industries and their corporations. The current study sought to forecast oil demand in Ghana for the next decade. The variables analyzed in this study were Petroleum and other liquids, motor gasoline, distillate fuel, and liquefied petroleum gases (LPG). The study utilized three univariate models; thus, linear regression, exponential regression, and exponential smoothing for forecasting various oil components. The linear regression model was deemed a better fit for the analysis of most of the variables. Furthermore, the findings revealed that the LPG growth rate is faster and requires less time to double in numbers than the other energy sources. Also, the exponential smoothing model was ineffective and inefficient. Overall, the demand for oil components analyzed will follow an increasing pattern from 2017 to 2027.
\end{abstract}

Keywords: Forecasting; Oil demand; Oil consumption; Energy; Ghana Africa

\section{Introduction}

Merchants and dealers involved in the oil markets view global oil demand and its output forecasts as essential instruments. Speculative and non-quantifiable variables have essential roles in evaluating shortrun price fluctuations on the spot and in future markets. Oil prices escalating will lead to oil-consuming nations' economic contraction and inflation, adversely affecting the world economy. Otherwise, a sharp drop in oil price might preclude the economic growth of the countries producing oil and thus create political turmoil and civil upheaval (Chen et al., 2018).

Developing countries like Ghana, Nigeria, Ivory Coast, among others, sometimes struggle to meet the demands of their citizens, and oil is a clear example of it. Bourgeois and technical components that affected each end energy category over the past decade have increased Ghana's demand for crude oil and refined petroleum products. Ghana's oil consumption has increased substantially, and this has shaken many energy experts. The function of energy resources in satisfying, among others, the needs of households, factories, transportation, and agriculture in any economy cannot be overplayed.

Multiple forms of energy sources are needed to meet the demand for lighting, cooking, generating electricity, among many other uses. Ghana's energy demand exceeds energy supply (Mensah et al., 2016). In Ghana's energy sector, light crude oil is the main energy source that powers the electricity output of thermal plants, apart from natural gas. As a multifunctional energy source heavily consumed in most countries, the oil helps multiple sectors of an economy. Due to it being a very significant form of energy for all economies, oil production and consumption are inextricably related to industrialization, sustainable development and economic growth. 
In 2016, the government of Ghana decided to launch a new policy which stated one district, one factory. With such expansion and development, the country will be aiming at growing its economy. Still, the demand for oil will increase due to the industrialization tactics being adopted to implement such a policy. With the amount of oil consumed significantly increasing and thus affecting the economic growth of Ghana in the process, the data from the US EIA International Energy Statistics database shows that there have been some variations in oil consumption values in Ghana since 2003 (see Figure 1).

From Figure 1, Petroleum and Other Liquid consumption reached its highest peak in 2017 with an amount of 88TBPD (Total Barrels Per Day) and its lowest peak of 39TBPD in 2003. Motor Gasoline consumption can also be seen experiencing variations in its values, reaching its highest peaks of 27TBPD in 2013, 2015 and 2017. Jet Fuel consumption, Residual Fuel Oil consumption and Liquefied Petroleum Gases consumption (LPG) also reached their highest peak in 2017 with values of 4TBPD, 2TBPD, and 9TBPD, respectively. Kerosene consumption, Distillate Fuel Oil consumption, and Other Refined Products consumption also had recorded values of 3.6TBPD, 39TBPD and 14TBPD, respectively, as their highest peak in the years 2008, 2015 and 2016, respectively.

This study aims to forecast oil demand in Ghana for the next ten years, taking into account the intensifying nature of oil demand in Ghana. To examine the amount of oil consumed in Ghana annually and estimate the dynamics of the various types of oil that influence the aggregate oil demand in Ghana are the key objectives operationalized from the main aim of this study. The subsequent sections of this study are arranged as follows: Section 2 delves into the literature review highlighting underlying concepts used to perform this study. Section 3 outlines the research methodology and approach, whilst sections 4 and 5 deals with results and discussions and, finally, the study concludes with recommendations.

\section{Literature Review}

Underlying works of literature that form the basis for conducting this research are discussed in this section. The section describes the strengths and shortcomings of current literature based on the role of oil in the energy sector in Ghana and oil forecasting, with key influencing factors affecting oil and its demand in general.

\subsection{The role of oil in Ghana's energy sector}

"Supply chains are the veins of an economy" (Mahmoudi et al., 2021), and the energy sector enables the smooth flow of supply in these veins. According to the world's economic and human development indicators (HDI), the energy sector is a crucial component that drives economic growth and development. The production and usage of oil can accelerate or impede economic growth as an essential economic element. Over the last decade, oil demand has risen all over the world, leading to high prices.

Between 1980 and 2008, the price of crude oil fluctuated dramatically, with an average price of $\$ 32.31$ (bbl), a minimum price of $\$ 12.72(\mathrm{bbl})$ and a maximum price of $\$ 140(\mathrm{bbl})$ respectively (Abledu et al., 2013). A host of academic studies like that of Richardson et al. (2010), and Zhang et al. (2013) delved into the increasing rate of energy demands or consumption for both developed and least developed countries. The studies, as mentioned above, highlighted key determinants or indicators that culminate into total consumption or extrapolated elements of various energy forms.

Ghana discovered oil in the year 2007. In 2010, the country began exploiting this resource, and the country has realized its long-standing dream of improving its socio-economic growth with oil revenues through subsequent discoveries. Ghana's energy sector has been prominent in numerous government policies, such as initiatives to attain sustainable energy use to minimize the environmental impact, increase access to new energy sources, and make energy products accessible and inexpensive for Ghanaians (Mensah et al., 2016). A study by Ackah (2014) found that demand for natural gas is primarily driven by income, population, prices, and industrial production share when it modelled Ghana's aggregate residential and industrial demand for natural gas. But the the oil demand was not studied.

High growth rates of economic production and personal income are closely linked to the changing oil requirements in Ghana. Increased demand for petrochemical feedstock, including naphtha-based petrochemicals, which are close in composition to motor gasoline, drives the growth in production in the industrial sector (Abledu et al., 2013). Duku et al. (2011) noted that Ghana's energy consumption had increased significantly due to population growth and rapid urban growth. A continuing 


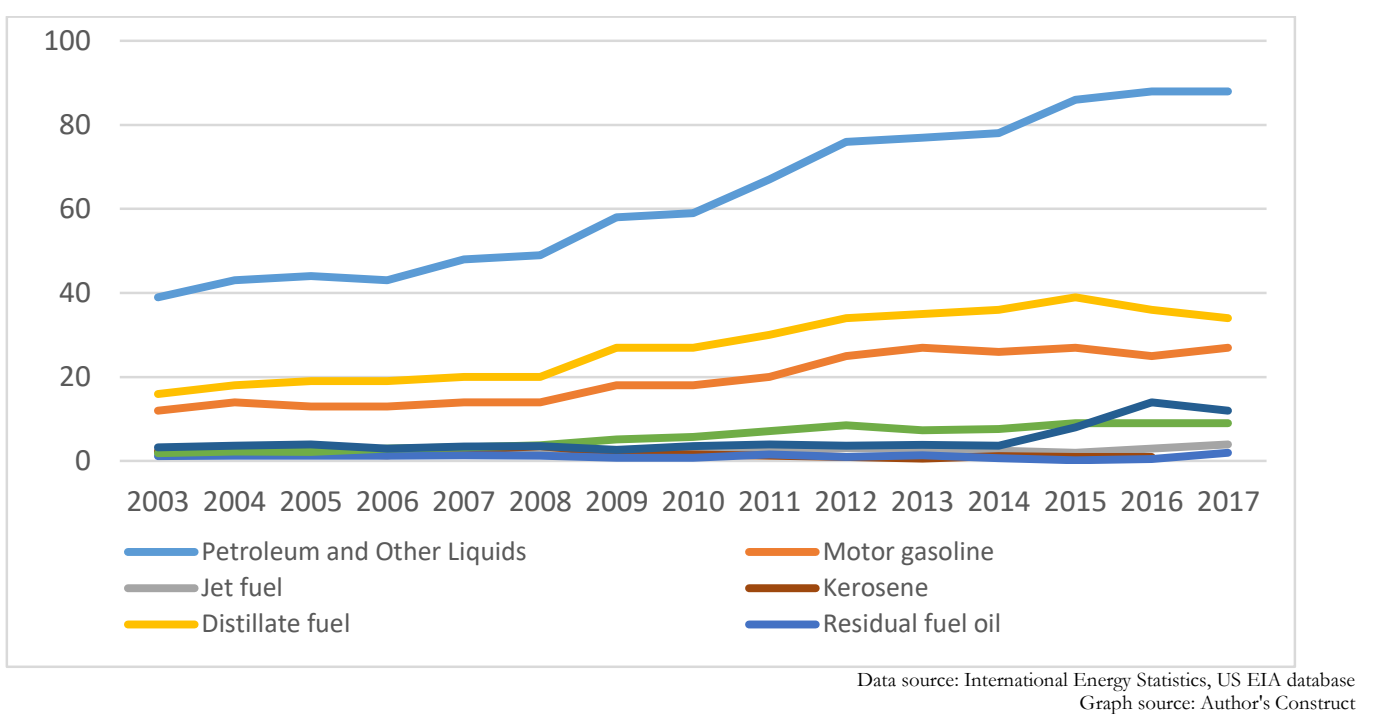

Figure 1. Ghana's annual oil consumption between 2003 and 2017

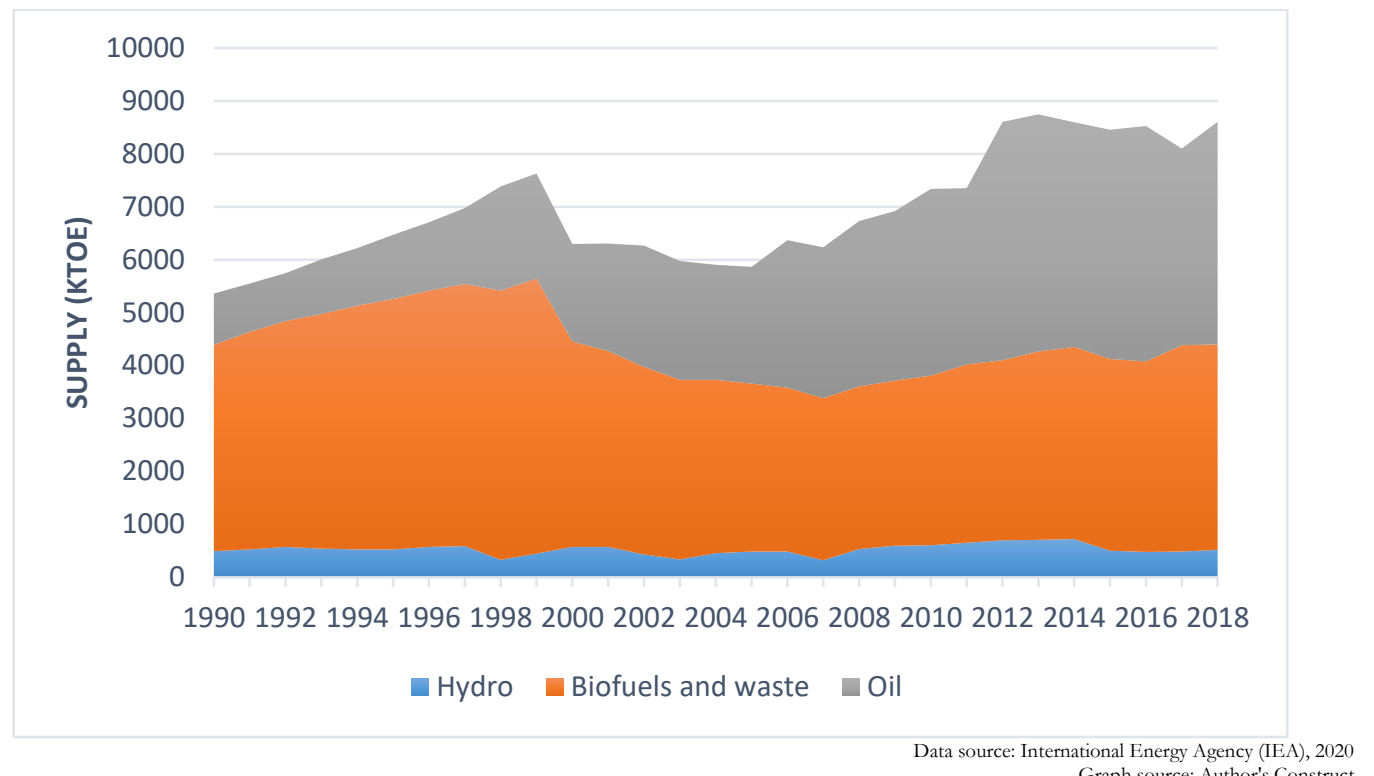

Figure 2. Ghana's energy supply between 1990 and 2018

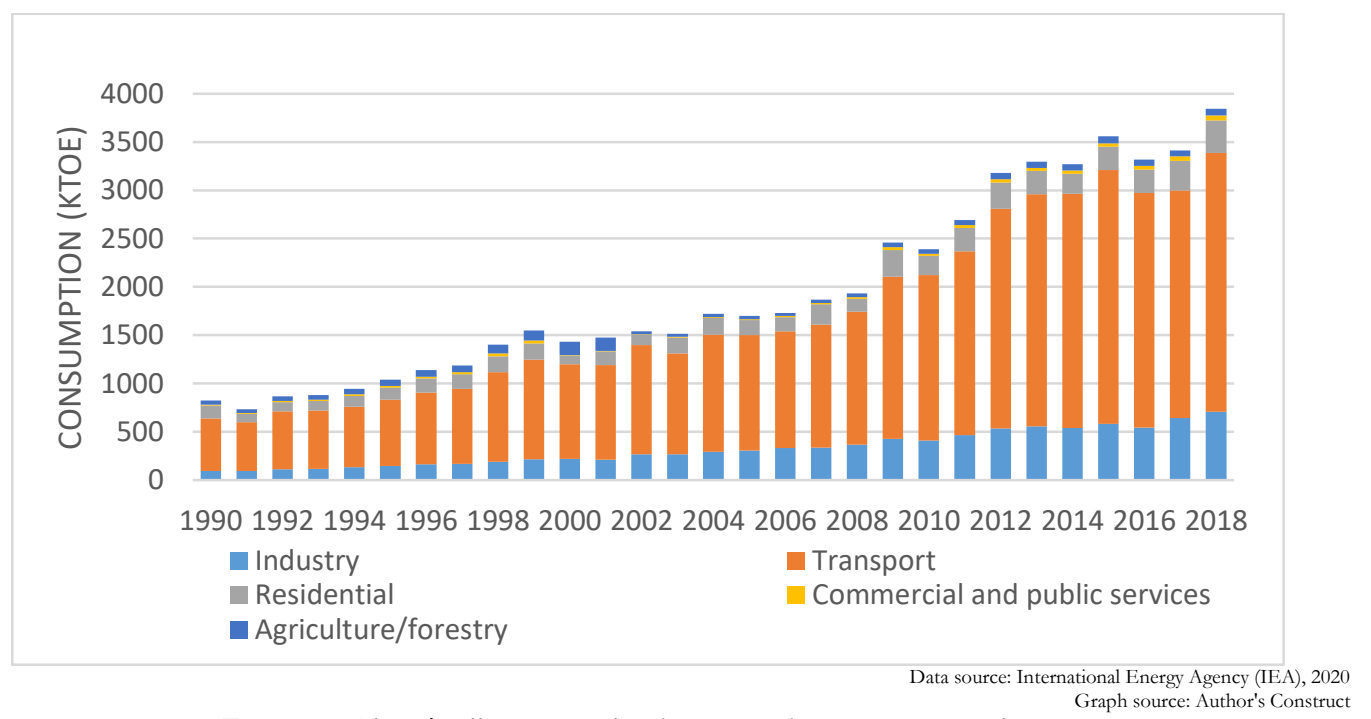

Figure 3. Ghana's oil consumption by sectors between 1990 and 2018 
demographic shift from rural to urban areas drives the increase in incomes and the resulting changes in oil demand. The rising urban population demands new vehicles and highways, thus increasing the demand for oil in the transport sector.

\subsection{Oil Forecasting}

The significance of the energy sector and energy forecasts has not been sufficiently addressed for the countries like Ghana. A vast amount of literature has been written about oil, determining the key variables that affect it. Some of this literature takes a toll on forecasting the aggregate demand, whereas some adopt the disaggregate demand for exploration. In empirical research, approaches based on the ex-ante best individual forecasting model are effective, but on average, forecast combinations have been found to generate effective forecasts (Timmermann, 2006).

Forecasting of oil demand and supply plays an essential role in a country's development agenda. Several models have been used in the existing literature by several scholars, researchers and organizations to make short, medium, and long-term projections. Notwithstanding these, there is no specific forecasting model assigned to forecasters. However, some researchers commonly use some existing standard forecasting models to make projections that have yielded the needed results. Hence, standard forecasting models could be selected based on a researcher's objectives and the results the researcher seeks to achieve. Such instances include $\mathrm{Li}$ et al. (2018) who developed 26 combination models using the traditional combination method to avoid overfitting and increase prediction accuracy. Furthermore, Wang et al. (2011) used the Hubbert and Generalized Weng models to provide them with the basis for the empirical analysis of the variable they analyzed in their study. Also, Carlevaro et al. (1989) modelled and forecasted the world demand for oil on a regional basis in the short - run using a dynamic demand model. They concluded that their model deserved more changes to generate valuable forecasts for the oil industry. As such, several existing forecasting models require further revision.

Owing to the fact that some unaccounted factors interfere with the actual values of oil, during forecasting based on historical data, the actual value sometimes varies from the forecasted value. Comparing the forecasted value with the actual value produces the measured error if there's any. Therefore, some studies proposed that the mean absolute scaled error should be the standard accuracy measure for comparing forecast accuracy over collective time series. To confirm the effectiveness of their approach, Wang et al. (2018) evaluated their models using mean absolute error (MAE), mean absolute percentage error (MAPE), and root mean square error (RMSE).

Table 1. Summary of oil forecast related literature

\begin{tabular}{|c|c|c|c|c|}
\hline Year & Country of focus & Variable of forecast & Methodology & Literature \\
\hline 2009 & $\begin{array}{l}\text { United States, } \\
\text { Canada, Japan, } \\
\text { Australia }\end{array}$ & Oil consumption & $\begin{array}{c}\text { flexible fuzzy } \\
\text { regression algorithm }\end{array}$ & Azadeh et al. (2009) \\
\hline 2009 & Global & Oil production & Probabilistic estimate & Kontorovich (2009) \\
\hline 2009 & China & $\begin{array}{c}\text { Transport energy } \\
\text { demand }\end{array}$ & PLSR & Zhang et al. (2009) \\
\hline 2012 & China & $\begin{array}{l}\text { Petroleum product } \\
\text { consumption }\end{array}$ & $\begin{array}{c}\text { Bayesian linear } \\
\text { regression theory and } \\
\text { MCMC }\end{array}$ & Chai et al. (2012) \\
\hline 2012 & Iran & $\begin{array}{c}\text { Transport energy } \\
\text { demand }\end{array}$ & MLGP & $\begin{array}{c}\text { Forouzanfar et al. } \\
\text { (2012) }\end{array}$ \\
\hline 2013 & Global & Oil demand & STSM & Suleiman (2013) \\
\hline 2015 & Nigeria & Oil production & $\begin{array}{l}\text { M.A., SES, AF, Box- } \\
\text { Jenkings, Classical } \\
\text { Decomposition }\end{array}$ & $\begin{array}{c}\text { Aideyan \& Nima } \\
\text { (2015) }\end{array}$ \\
\hline 2015 & OPEC & Oil production & $\begin{array}{l}\text { Multi-cyclic Hubbert } \\
\text { Model }\end{array}$ & $\begin{array}{c}\text { Ebrahimi \& } \\
\text { Ghasabani (2015) }\end{array}$ \\
\hline 2015 & U.K., Norway & Oil production & $\begin{array}{c}\text { Monte - Carlo } \\
\text { method }\end{array}$ & Fiévet et al. (2015) \\
\hline 2019 & China & Oil demand & STSM & Fatima et al. (2019) \\
\hline 2019 & India & Foreign oil & $\begin{array}{c}\text { NMGM-ARIMA and } \\
\text { NMGM-BP }\end{array}$ & Li \& Wang (2019) \\
\hline 2021 & Ghana & Oil demand & LR, ER and ETS & The current study \\
\hline $\begin{array}{l}\text { PLSR partial 1 } \\
\text { Monte Carlo } \\
\text { - linear autor } \\
\text { regression, EI }\end{array}$ & regression, M.A. movi & $\begin{array}{l}\text { rage, SES seasonal expone } \\
\text { ramming, STSM structural } \\
\text { NMGM-BP nonlinear me } \\
\text { ial smoothing }\end{array}$ & $\begin{array}{l}\text { moothing, A.F. adaptive filteri } \\
\text { eries model, NMGM-ARIMA } \\
\text { grey model - nonlinear backp }\end{array}$ & $\begin{array}{l}\text { NCMC Markov Chain } \\
\text { linear metabolic grey model } \\
\text { igation, LR Linear }\end{array}$ \\
\hline
\end{tabular}


Cheze et al. (2011) forecasted jet fuel consumption at the worldwide level and eight geographical zones by 2025 using dynamic panel-data econometrics. Their findings revealed that between 2008 and 2025 , the world's air traffic would increase by $100 \%$, with a growth rate of $4.7 \%$ annually. Moreover, the estimated demand of the world for jet fuel will increase by approximately $38 \%$, with an average growth rate of $1.9 \%$ annually. Al-Yousef (2004), in his study, proposed a model to predict crude oil consumption for some Asian countries over the period $1982-2002$. He concluded that GDP and price are important factors in oil demand. He also added that growth in GDP is an important element in the growth or fall in Asian countries' demand for crude oil. Due to briefness, table 1 contains other studies conducted by researchers about the forecasting of oil.

\section{Research Methodology}

This section focuses on the methodology and approach adopted in the current study for forecasting the demand for oil in Ghana for the next decade based on time series data. The study adopted three univariate models; linear regression model, exponential regression model, and exponential smoothing model. Microsoft Excel (2016 version) was used to run the models.

\subsection{Data collection}

The bp Statistical Review of World Energy (BP, 2020) ranked oil as the largest share of the energy mix, accounting for $33.1 \%$ and perhaps being a dominant economic growth tool in Africa. It also recorded 4096 thousand barrels per day as the consumption of oil in the whole of Africa. The current study sampled 15 years (2003 to 2017) time-series data of Ghana's annual oil consumption. Data from 2003 to 2015 was used for forecasting, and the 2016-2017 data was used for out-of-sample testing. The four energy sources were considered for forecasting; petroleum and other liquids, motor gasoline, distillate fuel oil, and liquefied petroleum gas (LPG). The oil consumption data set was gathered from the U.S. Energy Information Administration (www.eia.gov).

For the study to gain an insight into the vast reach of oil in Ghana, data pertaining to Ghana's energy sector for the period 1990 to 2018 were also gathered. Ghana's energy supply and Ghana's oil consumption by sectors data were obtained from the International Energy Agency (www.iea.org) for this exploration. Data availability was the justification for choosing the period (1990 to 2018).

\subsection{Forecasting Techniques}

Descriptively, forecasting is carried out by testing time series data with a developed model or applying technical approaches. Over specific periods, distinct models have been tried to predict data, and accurate calculations are needed to determine the accuracy of such models. Time series models used for forecasting can be classified into univariate and multivariate models (Tularam \& Saeed 2016). In order to predict the values of a variable that acts as a response variable, univariate data analysis involves the use of past data and involves a distinct evaluation of the findings for each variable in the given data. Thus, the univariate analysis does not find the causation or correlation relationship between independent variables. This study adopted the univariate models, namely; linear regression models, exponential models and exponential smoothing models, for forecasting oil demand in Ghana for a decade. These models were selected due to (1) they are a widely used form of forecasting and (2) the characteristics the data used in this study possess.

3.2.1 Linear regression model. A linear regression (LR) model is a simple yet widely used form of forecasting. The model forms a linear relationship between the forecast variable $F$ and the single explanatory variable $Y$. In order to analyze the relationship between the variables, the model is defined as:

$$
F_{t}=\beta_{0}+\beta_{1} Y_{t}+\varepsilon
$$

where,

$\beta_{0}=$ the intercept

$\beta_{1}=$ the slope of the line 
$F_{t}=$ forecasted value for year $\mathrm{t}$

$Y_{t}=$ Year $\mathrm{t}$

$\varepsilon=$ the error term

The intercept $\beta_{0}$ represents the forecasted value of $F_{t}$ when the explanatory variable $\left(Y_{t}\right)=0$. And the slope of the line $\beta_{1}$ represents the average predicted change in the forecasted value $F_{-} t$ resulting from a one-unit increase or decrease in the explanatory variable $Y_{t}$. For further details, Sarstedt and Mooi (2014) can be consulted. In the current study, Microsoft Excel's built-in function was used for linear regression.

3.2.2 Exponential regression model. An exponential regression (ER) model is a nonlinear form of a regression model. It is used to model data that does not follow a linear pattern. Exponential regression is used to predict conditions in which development starts slowly and then elevates quickly without bounds or where decay begins speedily and then slows down to get closer and closer to zero. The model is developed as follows:

$$
F_{t}=\beta_{0} e^{\beta_{1} Y_{t}}+\varepsilon
$$

where,

$$
\begin{aligned}
& F_{t}=\text { forecasted value for year } \mathrm{t} \\
& Y_{t}=\text { Year } \mathrm{t} .
\end{aligned}
$$

The coefficients $\beta_{0}$ and $\beta_{1}$ are obtained from the graph (data). For further details, Davidov and Zelen (2000) can be consulted. In the current study, Microsoft Excel's built-in function was used for exponential regression.

3.2.3 Exponential Smootbing technique. The exponential smoothing model was first suggested in the late 1950s. This approach is acceptable for forecasting data without a specific trend or seasonal pattern. The exponential smoothing model developed to examine the data is specified as:

$$
\begin{gathered}
L_{0}=\frac{1}{n} \sum_{t=1}^{n} D_{t} \\
F_{t+1}=L_{t} \\
L_{t+1}=\alpha D_{t+1}+(1-\alpha) L_{t}
\end{gathered}
$$

where,

$n=$ number of years

$D_{t}=$ actual demand at year $\mathrm{t}$

$D_{t+1}=$ current year's actual demand

$L_{0}=$ forecast demand for year 1

$L_{t}=$ previous year's forecast demand

$L_{t+1}=$ current year's forecast demand

$\alpha=$ smoothing constant; $0<\alpha<1$.

For further details, Chopra and Meindl (2015: Chapter 7) can be consulted. Microsoft Excel's builtin function for exponential triple smoothing (ETS) was used in the current study. 
Table 2. Forecasting the consumption of petroleum and other liquids

\begin{tabular}{|c|c|c|c|c|c|c|c|c|c|}
\hline Year & Actual data & LR & ER & ETS & Cumulative & RGR & RGR (mean) & $D t$ & $D t$ (mean) \\
\hline 2003 & 39 & 34.83 & 35.28 & 47.09 & 39 & - & & & \\
\hline 2004 & 43 & 38.88 & 37.79 & 50.24 & 82 & 0.74 & \multirow[t]{12}{*}{0.25} & 0.99 & \multirow[t]{12}{*}{2.25} \\
\hline 2005 & 44 & 42.92 & 40.48 & 53.38 & 126 & 0.43 & & 1.54 & \\
\hline 2006 & 43 & 46.96 & 43.37 & 56.52 & 169 & 0.29 & & 1.92 & \\
\hline 2007 & 48 & 51.01 & 46.46 & 59.66 & 217 & 0.25 & & 2.08 & \\
\hline 2008 & 49 & 55.05 & 49.77 & 62.81 & 266 & 0.20 & & 2.28 & \\
\hline 2009 & 58 & 59.10 & 53.31 & 65.95 & 324 & 0.20 & & 2.32 & \\
\hline 2010 & 59 & 63.14 & 57.11 & 69.09 & 383 & 0.17 & & 2.48 & \\
\hline 2011 & 67 & 67.18 & 61.17 & 72.23 & 450 & 0.16 & & 2.52 & \\
\hline 2012 & 76 & 71.23 & 65.53 & 75.38 & 526 & 0.16 & & 2.55 & \\
\hline 2013 & 77 & 75.27 & 70.20 & 78.52 & 603 & 0.14 & & 2.68 & \\
\hline 2014 & 78 & 79.32 & 75.20 & 81.66 & 681 & 0.12 & & 2.80 & \\
\hline 2015 & 86 & 83.36 & 80.55 & 84.80 & 767 & 0.12 & & 2.82 & \\
\hline 2016 & 88 & 87.40 & 86.29 & 87.95 & 87.40 & - & & - & \\
\hline 2017 & 88 & 91.45 & 92.44 & 91.09 & 178.85 & 0.72 & \multirow[t]{11}{*}{0.25} & 1.03 & \multirow[t]{11}{*}{2.28} \\
\hline 2018 & & 95.49 & 99.02 & 94.23 & 274.34 & 0.43 & & 1.54 & \\
\hline 2019 & & 99.54 & 106.07 & 97.37 & 373.88 & 0.31 & & 1.87 & \\
\hline 2020 & & 103.58 & 113.63 & 100.52 & 477.46 & 0.24 & & 2.10 & \\
\hline 2021 & & 107.62 & 121.72 & 103.66 & 585.08 & 0.20 & & 2.29 & \\
\hline 2022 & & 111.67 & 130.39 & 106.80 & 696.75 & 0.17 & & 2.44 & \\
\hline 2023 & & 115.71 & 139.67 & 109.94 & 812.46 & 0.15 & & 2.57 & \\
\hline 2024 & & 119.76 & 149.62 & 113.09 & 932.22 & 0.14 & & 2.68 & \\
\hline 2025 & & 123.80 & 160.28 & 116.23 & 1056.02 & 0.12 & & 2.78 & \\
\hline 2026 & & 127.84 & 171.69 & 119.37 & 1183.86 & 0.11 & & 2.86 & \\
\hline 2027 & & 131.89 & 183.92 & 122.51 & 1315.75 & 0.11 & & 2.94 & \\
\hline $\begin{array}{c}\text { MAPE (\%) } \\
\text { in-sample }\end{array}$ & & 5.62 & 6.75 & 14.64 & & & & & \\
\hline $\begin{array}{l}\text { MAPE (\%) } \\
\text { out-of-sample }\end{array}$ & & 2.30 & 3.49 & 1.79 & & & & & \\
\hline
\end{tabular}

\subsection{Forecast Error Measurement}

It has been widely recognized that forecasts are always inaccurate. Therefore, they should be accompanied by both the expected value of the forecast and a measure of forecast error (Javed $e t$ al., 2020b; Ofosu-Adarkwa et al., 2020). Following Javed et al. (2020a), the Mean Absolute Percentage Error (MAPE) was used to test the performance of the forecasting techniques. The MAPE formula is denoted by:

$$
\operatorname{MAPE}(\%)=\frac{1}{n} \sum_{k=1}^{n}\left|\frac{x(k)-\hat{x}(k)}{x(k)}\right| \times 100 \%
$$

where,

$x(k)=$ actual values

$\hat{x}(k)=$ simulated values

$n=$ number of years. 
Table 3. Forecasting the consumption of motor gasoline

\begin{tabular}{|c|c|c|c|c|c|c|c|c|c|}
\hline Year & Actual data & LR & $E R$ & ETS & Cumulative & RGR & RGR (mean) & $D t$ & $D t$ (mean) \\
\hline 2003 & 12 & 10.05 & 10.59 & 28.25 & 12 & - & & & \\
\hline 2004 & 14 & 11.47 & 11.42 & 28.25 & 26 & 0.77 & \multirow[t]{12}{*}{0.25} & 0.95 & \multirow[t]{12}{*}{2.24} \\
\hline 2005 & 13 & 12.89 & 12.32 & 28.25 & 39 & 0.41 & & 1.60 & \\
\hline 2006 & 13 & 14.31 & 13.29 & 28.25 & 52 & 0.29 & & 1.94 & \\
\hline 2007 & 14 & 15.72 & 14.34 & 28.25 & 66 & 0.24 & & 2.13 & \\
\hline 2008 & 14 & 17.14 & 15.47 & 28.24 & 80 & 0.19 & & 2.34 & \\
\hline 2009 & 18 & 18.56 & 16.69 & 28.24 & 98 & 0.20 & & 2.29 & \\
\hline 2010 & 18 & 19.98 & 18.01 & 28.24 & 116 & 0.17 & & 2.47 & \\
\hline 2011 & 20 & 21.39 & 19.43 & 28.24 & 136 & 0.16 & & 2.53 & \\
\hline 2012 & 25 & 22.81 & 20.96 & 28.24 & 161 & 0.17 & & 2.47 & \\
\hline 2013 & 27 & 24.23 & 22.62 & 28.24 & 188 & 0.16 & & 2.56 & \\
\hline 2014 & 26 & 25.65 & 24.40 & 28.24 & 214 & 0.13 & & 2.74 & \\
\hline 2015 & 27 & 27.06 & 26.32 & 28.24 & 241 & 0.12 & & 2.82 & \\
\hline 2016 & 25 & 28.48 & 28.40 & 28.24 & 28.40 & - & & - & \\
\hline 2017 & 27 & 29.90 & 30.64 & 28.23 & 59.04 & 0.73 & \multirow[t]{11}{*}{0.27} & 1.01 & \multirow[t]{11}{*}{2.17} \\
\hline 2018 & & 31.32 & 33.05 & 28.23 & 92.09 & 0.44 & & 1.50 & \\
\hline 2019 & & 32.73 & 35.66 & 28.23 & 127.75 & 0.33 & & 1.81 & \\
\hline 2020 & & 34.15 & 38.47 & 28.23 & 166.23 & 0.26 & & 2.03 & \\
\hline 2021 & & 35.57 & 41.51 & 28.23 & 207.74 & 0.22 & & 2.19 & \\
\hline 2022 & & 36.99 & 44.78 & 28.23 & 252.52 & 0.20 & & 2.33 & \\
\hline 2023 & & 38.40 & 48.31 & 28.23 & 300.83 & 0.18 & & 2.44 & \\
\hline 2024 & & 39.82 & 52.12 & 28.23 & 352.95 & 0.16 & & 2.53 & \\
\hline 2025 & & 41.24 & 56.23 & 28.23 & 409.18 & 0.15 & & 2.60 & \\
\hline 2026 & & 42.66 & 60.67 & 28.22 & 469.84 & 0.14 & & 2.67 & \\
\hline 2027 & & 44.08 & 65.45 & 28.22 & 535.29 & 0.13 & & 2.73 & \\
\hline $\begin{array}{l}\text { MAPE (\%) } \\
\text { in-sample }\end{array}$ & & 9.35 & 7.83 & 66.23 & & & & & \\
\hline $\begin{array}{l}\text { MAPE (\%) } \\
\text { out-of-sample }\end{array}$ & & 12.33 & 13.54 & 8.76 & & & & & \\
\hline
\end{tabular}

The Lewis scale (Javed et al., 2020a) was used for interpreting the MAPE values:

$$
\operatorname{MAPE}(\%)=\left\{\begin{array}{cr}
<10 \quad \text { Highly accurate forecast } \\
10 \sim 20 & \text { Good forecast } \\
20 \sim 50 & \text { Reasonable forecast } \\
>50 & \text { Inaccurate forecast }
\end{array}\right.
$$

\subsection{Growth Rate and Doubling Time Analyses}

Growth rate and doubling time analyses make forecasts more useful for decision-makers. The expression for the relative growth rate $(R G R)$ and doubling time $\left(D_{t}\right)$ are given by (Javed \& Liu, 2018; Quartey-Papafio et al., 2020):

$$
R G R=\left(\ln N_{2}-\ln N_{1}\right) /\left(t_{2}-t_{1}\right)
$$

Since in our study $t_{2}-t_{1}$ is one, the equation is further deduced to:

$$
R G R=\ln \left(N_{2} / N_{1}\right)
$$


Table 4. Forecasting the consumption of distillate fuel

\begin{tabular}{|c|c|c|c|c|c|c|c|c|c|}
\hline Year & $\begin{array}{c}\text { Actual } \\
\text { data }\end{array}$ & LR & ER & ETS & Cumulative & RGR & $\begin{array}{l}\mathrm{RGR} \\
\text { (mean) }\end{array}$ & $D t$ & $\begin{array}{c}D t \\
\text { (mean) }\end{array}$ \\
\hline 2003 & 16 & 14.20 & 15.66 & 14.84 & 16.00 & - & & & \\
\hline 2004 & 18 & 16.20 & 16.92 & 16.84 & 34.00 & 0.75 & \multirow[t]{12}{*}{0.25} & 0.98 & \multirow[t]{12}{*}{2.22} \\
\hline 2005 & 19 & 18.20 & 18.28 & 18.83 & 53.00 & 0.44 & & 1.51 & \\
\hline 2006 & 19 & 20.20 & 19.76 & 20.83 & 72.00 & 0.31 & & 1.88 & \\
\hline 2007 & 20 & 22.20 & 21.35 & 22.83 & 92.00 & 0.25 & & 2.10 & \\
\hline 2008 & 20 & 24.20 & 23.07 & 24.83 & 112.00 & 0.20 & & 2.32 & \\
\hline 2009 & 27 & 26.20 & 24.93 & 26.83 & 139.00 & 0.22 & & 2.23 & \\
\hline 2010 & 27 & 28.20 & 26.94 & 28.83 & 166.00 & 0.18 & & 2.42 & \\
\hline 2011 & 30 & 30.20 & 29.11 & 30.83 & 196.00 & 0.17 & & 2.49 & \\
\hline 2012 & 34 & 32.20 & 31.46 & 32.82 & 230.00 & 0.16 & & 2.53 & \\
\hline 2013 & 35 & 34.20 & 33.99 & 34.82 & 265.00 & 0.14 & & 2.65 & \\
\hline 2014 & 36 & 36.20 & 36.73 & 36.82 & 301.00 & 0.13 & & 2.75 & \\
\hline 2015 & 39 & 38.20 & 39.69 & 38.82 & 340.00 & 0.12 & & 2.80 & \\
\hline 2016 & 36 & 40.20 & 42.89 & 40.82 & 40.20 & - & & - & \\
\hline 2017 & 34 & 42.20 & 46.34 & 42.82 & 82.40 & 0.72 & \multirow[t]{11}{*}{0.25} & 1.02 & \multirow[t]{11}{*}{2.27} \\
\hline 2018 & & 44.20 & 50.08 & 44.81 & 126.60 & 0.43 & & 1.54 & \\
\hline 2019 & & 46.20 & 54.11 & 46.81 & 172.80 & 0.31 & & 1.86 & \\
\hline 2020 & & 48.20 & 58.47 & 48.81 & 221.00 & 0.25 & & 2.10 & \\
\hline 2021 & & 50.20 & 63.18 & 50.81 & 271.20 & 0.20 & & 2.28 & \\
\hline 2022 & & 52.20 & 68.28 & 52.81 & 323.40 & 0.18 & & 2.43 & \\
\hline 2023 & & 54.20 & 73.78 & 54.81 & 377.60 & 0.15 & & 2.56 & \\
\hline 2024 & & 56.20 & 79.72 & 56.81 & 433.80 & 0.14 & & 2.67 & \\
\hline 2025 & & 58.20 & 86.15 & 58.80 & 492.00 & 0.13 & & 2.77 & \\
\hline 2026 & & 60.20 & 93.09 & 60.80 & 552.20 & 0.12 & & 2.85 & \\
\hline 2027 & & 62.20 & 100.59 & 62.80 & 614.40 & 0.11 & & 2.93 & \\
\hline $\begin{array}{c}\text { MAPE (\%) } \\
\text { in-sample }\end{array}$ & & 6.31 & 4.85 & 6.11 & & & & & \\
\hline $\begin{array}{l}\text { MAPE (\%) } \\
\text { out-of-sample }\end{array}$ & & 17.89 & 27.72 & 19.66 & & & & & \\
\hline
\end{tabular}

The time needed for the variables analyzed to double in numbers for a given $R G R$ is measured by the $D_{t}$ and this is denoted as:

$$
D_{t}=\left(t_{2}-t_{1}\right) \ln \left[\frac{2}{\ln N_{2}-\ln N_{1}}\right]
$$

or,

$$
D_{t}=\ln (2 / R G R)
$$

where,

$N_{2}=$ analyzed variable's cumulative number in the year $t_{2}$

$N_{1}=$ analyzed variable's cumulative number in the year $t_{1}$

A general assessment of the variations of the different variables between the actual trend and the expected trend is useful but challenging. The traditional $R G R$ and $D_{t}$ cannot solve the problem, especially when the forecasted trend is different from the historical trend. Javed and Liu (2018) solved this problem by introducing a system for estimating the Synthetic Relative Growth Rate $\left(R G R_{\text {synthetic }}\right)$ 
Table 5. Forecasting the consumption of liquefied petroleum gases (LPG)

\begin{tabular}{|c|c|c|c|c|c|c|c|c|c|}
\hline Year & $\begin{array}{c}\text { Actual } \\
\text { data }\end{array}$ & $L R$ & ER & ETS & Cumulative & RGR & $\begin{array}{l}R G R \\
\text { (mean) }\end{array}$ & $D t$ & $\begin{array}{c}D t \\
\text { (mean) }\end{array}$ \\
\hline 2003 & 1.9 & 1.30 & 2.02 & 1.32 & 1.90 & - & & & \\
\hline 2004 & 2.3 & 1.94 & 2.32 & 1.95 & 4.20 & 0.79 & \multirow[t]{12}{*}{0.30} & 0.92 & \multirow[t]{12}{*}{2.03} \\
\hline 2005 & 2.2 & 2.57 & 2.67 & 2.59 & 6.40 & 0.42 & & 1.56 & \\
\hline 2006 & 3 & 3.21 & 3.06 & 3.22 & 9.40 & 0.38 & & 1.65 & \\
\hline 2007 & 3.3 & 3.84 & 3.52 & 3.86 & 12.70 & 0.30 & & 1.89 & \\
\hline 2008 & 3.8 & 4.48 & 4.04 & 4.49 & 16.50 & 0.26 & & 2.03 & \\
\hline 2009 & 5.2 & 5.11 & 4.64 & 5.12 & 21.70 & 0.27 & & 1.99 & \\
\hline 2010 & 5.7 & 5.75 & 5.33 & 5.76 & 27.40 & 0.23 & & 2.15 & \\
\hline 2011 & 7.1 & 6.38 & 6.12 & 6.39 & 34.50 & 0.23 & & 2.16 & \\
\hline 2012 & 8.5 & 7.02 & 7.02 & 7.03 & 43.00 & 0.22 & & 2.21 & \\
\hline 2013 & 7.3 & 7.65 & 8.07 & 7.66 & 50.30 & 0.16 & & 2.55 & \\
\hline 2014 & 7.6 & 8.28 & 9.26 & 8.29 & 57.90 & 0.14 & & 2.65 & \\
\hline 2015 & 9 & 8.92 & 10.64 & 8.93 & 66.90 & 0.14 & & 2.63 & \\
\hline 2016 & 9 & 9.55 & 12.21 & 9.56 & 9.55 & - & & - & \\
\hline 2017 & 9 & 10.19 & 14.03 & 10.20 & 19.74 & 0.73 & \multirow[t]{11}{*}{0.25} & 1.01 & \multirow[t]{13}{*}{2.24} \\
\hline 2018 & & 10.82 & 16.11 & 10.83 & 30.56 & 0.44 & & 1.52 & \\
\hline 2019 & & 11.46 & 18.49 & 11.46 & 42.02 & 0.32 & & 1.84 & \\
\hline 2020 & & 12.09 & 21.24 & 12.10 & 54.11 & 0.25 & & 2.07 & \\
\hline 2021 & & 12.73 & 24.39 & 12.73 & 66.84 & 0.21 & & 2.25 & \\
\hline 2022 & & 13.36 & 28.01 & 13.37 & 80.20 & 0.18 & & 2.40 & \\
\hline 2023 & & 14.00 & 32.16 & 14.00 & 94.20 & 0.16 & & 2.52 & \\
\hline 2024 & & 14.63 & 36.93 & 14.63 & 108.83 & 0.14 & & 2.63 & \\
\hline 2025 & & 15.27 & 42.41 & 15.27 & 124.09 & 0.13 & & 2.72 & \\
\hline 2026 & & 15.90 & 48.70 & 15.90 & 139.99 & 0.12 & & 2.81 & \\
\hline 2027 & & 16.53 & 55.92 & 16.54 & 156.53 & 0.11 & & 2.89 & \\
\hline $\begin{array}{c}\text { MAPE (\%) } \\
\text { in-sample }\end{array}$ & & 11.54 & 10.99 & 11.56 & & & & & \\
\hline $\begin{array}{l}\text { MAPE (\%) } \\
\text { out-of-sample }\end{array}$ & & 9.68 & 45.78 & 9.77 & & & & & \\
\hline
\end{tabular}

and Synthetic Doubling Time ( $\left.D_{\text {synthetic }}\right)$. This approach effectively gives the overall picture of the $R G R$ and $D_{t}$. The formulas are given by;

$$
\begin{gathered}
R G R_{\text {synthetic }}=\theta \cdot\left(R G R_{\text {actual }}\right)+(1-\theta) \cdot R G R_{\text {forecast }} \\
D_{\text {synthetic }}=\theta \cdot\left(D_{\text {actual }}\right)+(1-\theta) \cdot D_{\text {forecast }}
\end{gathered}
$$

where,

$R G R_{\text {actual }}=$ relative growth rate derived through actual data

$R G R_{\text {forecast }}=$ relative growth rate derived through forecasted data

$D_{\text {actual }}=$ doubling time derived through actual data

$D_{\text {forecast }}=$ relative growth rate derived through forecasted data

$\theta=$ the weighing coefficient, valued at 0.5 in the current study 
For further details on relative growth rate and doubling time analyses and their synthetic versions, Javed and Liu (2018) is recommended.

\section{Results}

Results obtained from analyzing the data used for this study are discussed in this chapter. The data (2003-2017) were analyzed using Microsoft Excel 2016 version software. The periods 2016 and 2017 were used for out-of-sample testing. The linear regression models (LR), exponential regression models (ER) and exponential smoothing models (ETS) were used to forecast for oil demand in Ghana over the next ten years. The results of the analysis are summarized in Tables 2 to 5 . The MAPE was estimated to test the accuracy of the models. Relative growth rate $(R G R)$ and doubling time $\left(D_{t}\right)$ were also used to analyze the growth of the variables explored in this study. Furthermore, the Synthetic Relative Growth Rate $\left(R G R_{\text {synthetic }}\right)$ and Synthetic Doubling Time $\left(D_{\text {synthetic }}\right)$ were applied to assess the variations of the different variables between the actual trend and the expected trend.

Table 2 provides the results obtained for the variable Petroleum and other liquids. Both the Linear Regression and Exponential Regression provided highly accurate forecasts based on the MAPE scale adopted for this study. The Linear Regression instead had a higher forecasting accuracy as compared to the other models. The Linear Regression and Exponential Regression models developed for the Petroleum and other liquids variable are $F_{t}=4.044 Y_{t}-8065.3$ and $F_{t}=5 E-59 e^{0.0688 Y_{t}}$, respectively.

Table 3 provides the results obtained for the variable Motor gasoline. After analyzing the data, the results provided Linear Regression and Exponential Regression models $F_{t}=1.4176 Y_{t}-2829.4$ and $F_{t}=1 E-65 e^{0.0759 Y_{t}}$, respectively. The application of the ETS model for forecasting was ineffective for this variable. The Exponential Regression instead provided good forecasting results as compared to the other models.

Table 4 provides the results obtained for the variable Distillate fuel. After analyzing the data, the results provided Linear Regression and Exponential Regression models $F_{t}=2 Y_{t}-3991.8$ and $F_{t}=$ $6 E-67 e^{0.0775 Y_{t}}$, respectively. Although the application of all three of the forecasting models was effective for this variable, Linear Regression seemed better than Exponential Regression in this case because their out-of-sample errors had a big difference.

Table 5 provides the results obtained for the variable Liquefied Petroleum Gasses (LPG). After analyzing the data, the results provided Linear Regression and Exponential Regression models $F_{t}=$ $0.6346 Y_{t}-1269.8$ and $F_{t}=1 E-120 e^{0.1383 Y_{t}}$, respectively. Based on the comparison made between the three models' MAPE values, Linear Regression seemed better than Exponential Regression in this case because of the vast difference in their out-of-sample errors.

Moreover, the sequence obtained according to the $R G R$ based on the actual data are;

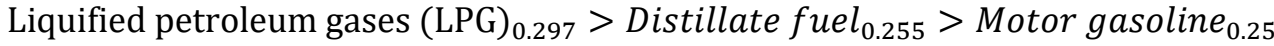 $>$ Petroleum and other liquids $s_{0.248}$}

Moreover, the sequence obtained according to the $D_{t}$ based on the actual data are;

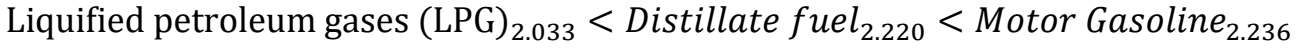

$$
\begin{aligned}
& <\text { Petroleum and other liquids } 2.249
\end{aligned}
$$

The above $R G R$ and $D_{t}$ provides insight into the relative growth rate for LPG and Distillate, which is increasing compared to Motor gasoline and Petroleum and other liquids. Furthermore, for a given $R G R$, LPG and Distillate fuel need less time to double in numbers than Motor gasoline and Petroleum and other liquids.

Also, the sequence obtained for the $R G R_{\text {synthetic }}$ are; 


\section{Liquified petroleum gases (LPG) $)_{0.275}>$ Motor Gasoline $_{0.258}>$ Distillate fuel $_{0.251}$ $>$ Petroleum and other liquids $s_{0.247}$}

And the sequence obtained for the $D_{\text {synthetic }}$ are;

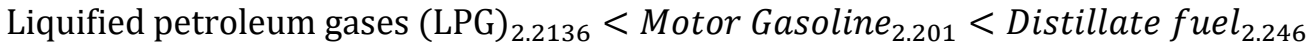 $<$ Petroleum and other liquids $s_{2.26}$}

According to the $R G R_{\text {synthetic }}$ LPG's growth rate is increasing faster than Motor Gasoline, Distillate fuel and Petroleum and Other liquids. Furthermore, LPG requires less time to double in numbers according to the $D_{\text {synthetic }}$ then the other variables.

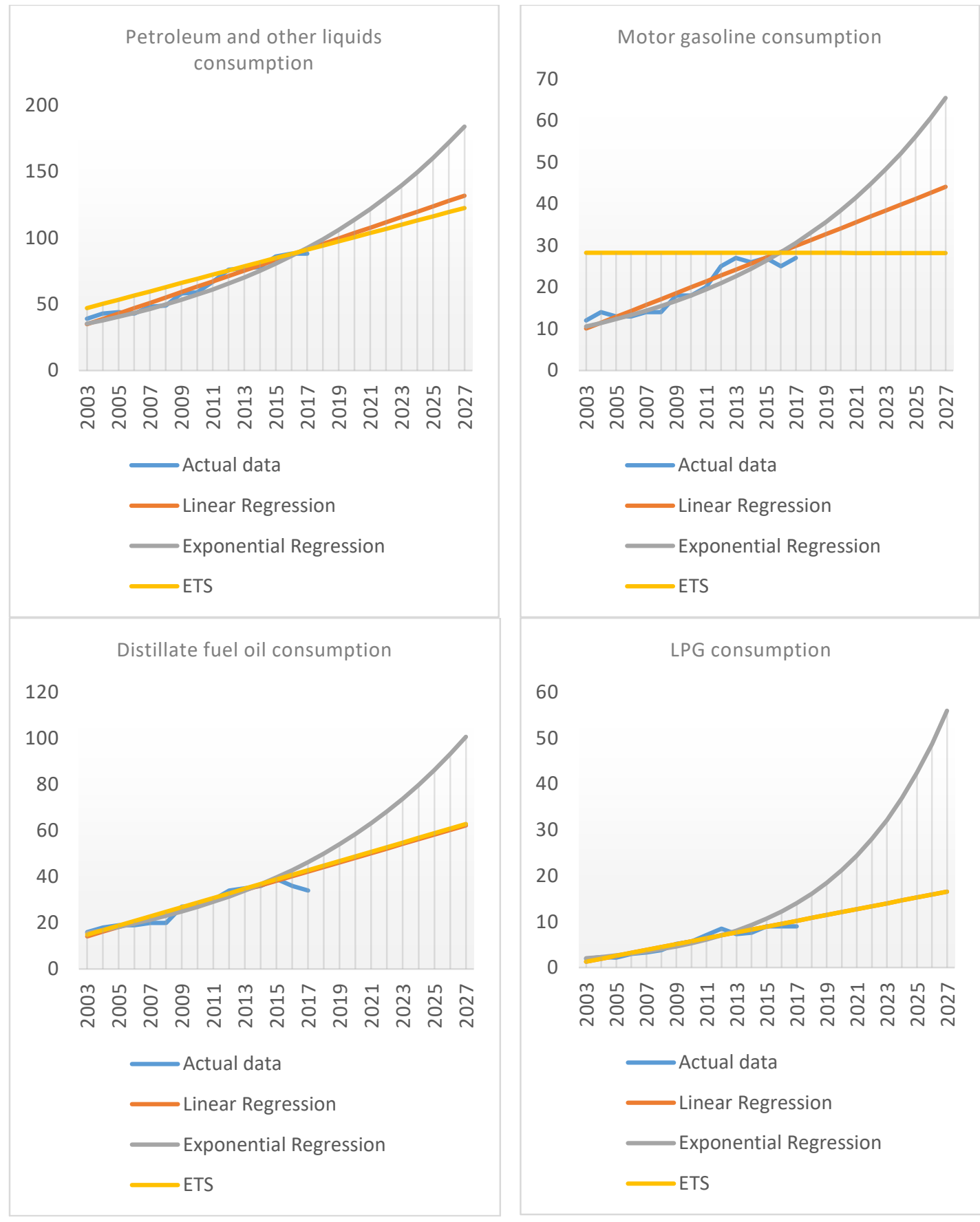

Figure 4. The forecasted values against the actual values (Annual, TBPD) 


\section{Discussion}

Ghana's energy demand surpasses the supply and, as confirmed by BP (2020), oil accounts for a large share of the energy mix and is a dominant economic growth tool in Africa. Considering the intensifying nature of oil demand in Ghana, the current study's objectives were to examine the amount of oil consumed in Ghana and estimate the dynamics of the various types of oil that influence the aggregate oil demand in Ghana. Unlike Ackah (2014), this study focused on forecasting Ghana's oil demand for the next decade. Wang et al. (2011) used two typical multicyclic models in forecasting oil, but, by a glance, almost all the analyzed variables' data in this study seem to depict traits of linear trends. In order to test this assumption, the Linear Regression, Exponential Regression, and ETS models were applied.

Oil demand is determined by a variety of factors, including changes in population and income. Findings agree with the results of Duku et al. (2011), who in their study revealed that as population or income increases, rapid growth in urbanization occurs. They highlighted how people's behaviour or lifestyle changes when their income levels change. They tend to settle or opt for superior goods instead of inferior goods. For instance, when a person's income increases, they will opt to purchase cars or other automobiles, use flights and other crude oil-related products. Bearing the current economic status per the World Bank or the IMF's economic stratification of countries based on average income levels, considering the country's rapid population growth, Ghana is classified as a lower-middle-income country. The country is expected to depend heavily on oil in various sectors of its economy. Hence, this could affect the country's demand for oil over the next decade. Also, the introduction of Ghana's Single Spine Policy Structure (SSPS) in 2008/2009 as an economic tool and a state policy to enhance salaries of civil servants and other public workers was aimed to improve public workers' income levels. This policy could trickle down economic growth and development, which, in turn, would reduce poverty. Such policies, for instance, go a long way to affect income levels and people's purchasing power, and family sizes (population growth). This change drives the increase in incomes and results in an increase in oil demand.

The oil demand for the variables analyzed and forecasted all followed an increasing trend. By 2027, the oil demand for Petroleum and other liquids will be 131.89TBPD (see Table 2), motor gasoline will be 65.45TBPD (see Table 3), distillate fuel will be 62.20TBPD (see Table 4), and liquefied petroleum gases (LPG) will be 16.53TBPD (see Table 5). This continuous rise in the demand for oil may be attributed to the intent to improve the agricultural and industrial sector through the use of machinery, one district-one factory (industrialization) policy which is now in place, in the transformation of the economy of Ghana from a raw economy into an industrialized economy. An industrialized economy depends mainly on oil. USA and China are clear examples of such economies based on their emission rates and oil demand. If Ghana grows on such tangents, dependence on oil in the next decade and years to come will be high and thus, lead to an increase in the demand for oil.

Residual fuel oil and distillate fuel oil are used in furnaces such as power plants. Currently, residual fuel oil is not as highly utilized in Ghana as other oil components in this study. This assertion might be based on the assumption that; distillate fuel oil is rather used in place of residual oil in the energy sector of Ghana. Ghana's energy sector is highly dependent on thermal and hydroelectric power. In Ghana, T1 and T2 thermal plants in Takoradi, Akosombo hydroelectric, Bui, Karpower badges all depend on crude oil and gas as it stands. Dependence on crude oil and gas would continue in the near future, considering the country's inability to explore other energy options. Solar and nuclear energy are not common due to the cost involved in obtaining solar panels, maintenance, the duration they last for, and technical know-how to manage them.

Applying the Linear Regression, Exponential Regression, and ETS models to the data used in this study provided results, which are ploted in Figure 4. The ETS was highly ineffective and inefficient for most of the variables. Although the ETS on some variables like distillate fuel was deemed a good fit with MAPE (\%) of 6.11 (highly accurate forecast based on the MAPE scale), it was somewhat not effective as compared to the other two models (LR and ER). The Linear Regression and Exponential Regression model deemed good fits for some variables, but the Linear Regression fit better in this study. For the distillate fuel and liquefied petroleum gases (LPG), the Linear Regression was chosen over the Exponential Regression due to a big difference in their out-of-sample errors. Thus, regarding distillate fuel, the in-sample error for Linear Regression was 6.31 while that of the Exponential Regression was 
4.85. But, their out-of-sample errors were $17.89 \%$ and $27.72 \%$, respectively. This study, therefore, confirmed the assumption that almost all the data used in this study depict a linear trend.

\section{Conclusion and recommendations}

This study focused on forecasting oil demand for the next decade while analyzing the components of oil that influence its aggregate demand in Ghana. The period 2003 to 2017 was chosen due to the availability of data. The univariate models, namely linear regression, exponential regression, and exponential smoothing, were employed to achieve the overall objectives of this study. Among the models employed for the present study, the linear regression model proved to be the most suitable model for forecasting oil demand in Ghana, considering the variables set out for this study. The exponential smoothing model was highly ineffective and inefficient in this study. Furthermore, the production and consumption of oil play a significant role in Ghana's economic growth and development.

The one-district-one factory (industrialization) policy, among other economic policies, when effectively implemented, would validate increasing demand for oil over the next decade, as highlighted in this study. Poor implementation of these policies would somewhat affect the oil demand, as purported in this study. Additionally, variables like kerosene, jet fuel, residual fuel, and other refined products can be included in future studies for analysis. The preliminary investigation found that the accurate forecast of these variables is a big challenge for the three statistical models because of the vast variation in their demand. Thus, better forecasting models such as multivariate grey forecasting models can be used for them in the future. Also, the post-COVID uncertainties can be incorporated in future studies. As the industries, organizations and consumers are heading towards alternative energy and electric vehicles are likely to dominate the automobile industry of the future, how the oil demand would respond to such drastic changes in the market and consumer behaviour is an area that needs further exploration.

\section{References}

Abledu, G. K., Agyemang, B., \& Reubin, S. (2013). Forecasting Demand for Petroleum Products in Ghana using Time Series Models. Journal of Economics and Sustainable Development, 4(17), 129-141.

Ackah, I. (2014). Determinants of natural gas demand in Ghana. Opec Energy Review, 38(3), 272-295. https://doi.org/10.1111/opec.12026.

Aideyan, H. O., \& Nima, M. (2015). Market Analysis and Forecasting of Oil and Gas (Lubricant) Management In Nigeria - A Case Study of Grand Petroleum. International Journal of Economics, Commerce and Management, 3(6), 23-35.

Al-Yousef, N. A. (2004). Modeling and Forecasting the demand for Crude Oil in Asian Countries. Energy \& Security in the Changing World, 2004 International Conference.

Azadeh, A., Khakestani, M., \& Saberi, M. (2009). A flexible fuzzy regression algorithm for forecasting oil consumption estimation. Energy Policy, 37(12), 5567-5579. https://doi.org/10.1016/J.ENPOL.2009.08.017

BP. (2020). Statistical Review of World Energy 2020. London: BP p.l.c. https://www.bp.com

Carlevaro, F., Romerio, F., Spierer, C., \& Gault, J. (1989). Modeling and Forecasting the World Demand for Oil. IFAC Proceedings Volumes, 22(17), 343-348. https://doi.org/10.1016/S1474-6670(17)52952-3

Chai, J., Wang, S., Wang, S., \& Guo, J. (2012). Demand Forecast of Petroleum Product Consumption in the Chinese Transportation Industry. Energies, 5(3), 577-598. https://doi.org/10.3390/en5030577

Chen, Y., Zhang, C., He, K., \& Zheng, A. (2018). Multi-step-ahead crude oil price forecasting using a hybrid grey wave model. Physica A: Statistical Mechanics and its Applications, 501, 98-110. https://doi.org/10.1016/j.physa.2018.02.061

Chèze, B., Gastineau, P., \& Chevallier, J. (2011). Forecasting world and regional aviation Jet-Fuel demands to the mid term (2025). Energy Policy, 39(9), 5147-5158. https://doi.org/10.1016/J.ENPOL.2011.05.049

Chopra, S., \& Meindl, P. (2015). Supply Chain Management: Strategy, Planning, and Operation (6th ed.). Pearson.

Davidov, O., \& Zelen, M. (2000). Exact tests for exponential regression. Journal of Statistical Planning and Inference, 88(1), 87-97. https://doi.org/10.1016/S0378-3758(99)00202-5

Duku, M. H., Gu, S., \& Hagan, E. B. (2011). A comprehensive review of biomass resources and biofuels potential in Ghana. Renewable \& Sustainable Energy Reviews, 15(1), 404-415. https://doi.org/10.1016/j.rser.2010.09.033

Ebrahimi, M., \& Ghasabani, N. C. (2015). Forecasting OPEC crude oil production using a variant Multicyclic Hubbert Model. Journal of Petroleum Science and Engineering, 133, 818-823. https://doi.org/10.1016/J.PETROL.2015.04.010 
Fatima, T., Xia, E., \& Ahad, M. (2019). Oil demand forecasting for China: a fresh evidence from structural time series analysis. Environment, Development and Sustainability, 21(3), 1205-1224. https://doi.org/10.1007/s10668-018-0081-7

Fiévet, L., Forró, Z., Cauwels, P., \& Sornette, D. (2015). A general improved methodology to forecasting future oil production: Application to the U.K. and Norway. Energy, 79, 288-297. https://doi.org/10.1016/J.ENERGY.2014.11.014

Forouzanfar, M., Doustmohammadi, A., \& Hasanzadeh, S. (2012). Transport energy demand forecast using multilevel genetic programming. Applied Energy, 91(1), 496-503. https://doi.org/10.1016/J.APENERGY.2011.08.018

Javed, S. A., \& Liu, S. (2018). Predicting the research output/growth of selected countries: application of Even G.M. (1, 1) and NDGM models. Scientometrics, 115(1), 395-413. https://doi.org/10.1007/S11192-017-25865

Javed, S. A., Zhu, B., \& Liu, S. (2020b). Forecast of biofuel production and consumption in top CO2 emitting countries using a novel grey model. Journal of Cleaner Production, 276, 123997. https://doi.org/10.1016/J.JCLEPRO.2020.123997

Javed, S.A., Ikram, M., Tao, L., \& Liu, S. (2020a). Forecasting Key Indicators of China's Inbound and Outbound Tourism: Optimistic-Pessimistic Method. Grey Systems: Theory and Application, 11(2), 265-287. https://doi.org/10.1108/GS-12-2019-0064

Kontorovich, A. E. (2009). Estimate of global oil resource and the forecast for global oil production in the $21 \mathrm{st}$ century. Russian Geology and Geophysics, 50(4), 237-242. https://doi.org/10.1016/J.RGG.2009.03.001

Li, J., Wang, R., Wang, J., \& Li, Y. (2018). Analysis and forecasting of the oil consumption in China based on combination models optimized by artificial intelligence algorithms. Energy, 144, 243-264. https://doi.org/10.1016/J.ENERGY.2017.12.042

Li, S., \& Wang, Q. (2019). India's dependence on foreign oil will exceed 90\% around 2025 - The forecasting results based on two hybridized NMGM-ARIMA and NMGM-BP models. Journal of Cleaner Production, 232, 137153. https://doi.org/10.1016/J.JCLEPRO.2019.05.314

Mahmoudi, A., Deng, X., Javed, S. A., \& Zhang, N. (2021). Sustainable Supplier Selection in Megaprojects through Grey Ordinal Priority Approach. Business Strategy and The Environment, 30, 318-339 https://doi.org/10.1002/bse.2623

Mensah, J. T., Marbuah, G., \& Amoah, A. (2016). Energy demand in Ghana: A disaggregated analysis. Renewable \& Sustainable Energy Reviews, 53, 924-935. https://doi.org/10.1016/j.rser.2015.09.035

Ofosu-Adarkwa, J., Xie, N., \& Javed, S. A. (2020). Forecasting $\mathrm{CO}_{2}$ Emissions of China's Cement Industry using Grey System Models and Emissions' Technical Conversion. Renewable and Sustainable Energy Reviews, 130, 109945. https://doi.org/10.1016/j.rser.2020.109945

Quartey-Papafio, T. K., Javed, S. A. \& Liu, S. (2020). Forecasting cocoa production of six major producers through ARIMA and grey models. Grey Systems: Theory and Application, 11(3), 434-462. https://doi.org/10.1108/GS04-2020-0050

Richardson, I., Thomson, M., Infield, D., \& Clifford, C. (2010). Domestic electricity use: A high-resolution energy demand model. Energy and Buildings, 42(10), 1878-1887. https://doi.org/10.1016/j.enbuild.2010.05.023

Sarstedt, M., \& Mooi, E. A. (2014). A Concise Guide to Market Research: The Process, Data, and Methods Using IBM SPSS Statistics (2nd ed.). Germany: Springer

Suleiman, M. (2013). Oil Demand, Oil Prices, Economic Growth and the Resource Curse: An Empirical Analysis. CiteSeer. http:/ / citeseerx.ist.psu.edu/viewdoc/summary?doi=10.1.1.677.8083

Timmermann, A. (2006). Chapter 4 - Forecast Combinations. In Handbook of Economic Forecasting (Vol. 1, pp. 135196). https://doi.org/10.1016/S1574-0706(05)01004-9

Tularam, G. A., \& Saeed, T. (2016). Oil-Price Forecasting Based on Various Univariate Time-Series Models. American Journal of Operations Research, 6(3), 226-235. https://doi.org/10.4236/AJOR.2016.63023

Wang, J., Feng, L., Zhao, L., Snowden, S., \& Wang, X. (2011). A comparison of two typical multicyclic models used to forecast the world's conventional oil production. Energy Policy, 39(12), 7616-7621. https://doi.org/10.1016/J.ENPOL.2011.07.043

Wang, Q., Song, X., \& Li, R. (2018). A novel hybridization of nonlinear grey model and linear ARIMA residual correction for forecasting U.S. shale oil production. Energy, 165, 1320-1331. https://doi.org/10.1016/J.ENERGY.2018.10.032

Zhang, H. L., Baeyens, J., Degrève, J., \& Cáceres, G. (2013). Concentrated solar power plants: Review and design methodology. Renewable \& Sustainable Energy Reviews, 22(22), 466-481. https://doi.org/10.1016/j.rser.2013.01.032

Zhang, M., Mu, H., Li, G., \& Ning, Y. (2009). Forecasting the transport energy demand based on PLSR method in China. Energy, 34(9), 1396-1400. https://doi.org/10.1016/J.ENERGY.2009.06.032 